\title{
Transition probabilities of several transitions in the Ar III and Ar IV spectra
}

\author{
S. Djeniže and S. Bukvić \\ Faculty of Physics, University of Belgrade PO Box 368, 11000 Belgrade, Serbia, Yugoslavia \\ Received 6 June 2000 / Accepted 22 September 2000

\begin{abstract}
Using the relative line intensity ratios method between transitions that belong to the same multiplet in the Ar III ( $4 \mathrm{~s}-4 \mathrm{p}, 4 \mathrm{~s}^{\prime}-4 \mathrm{p}^{\prime}$ and $4 \mathrm{p}^{\prime}-4 \mathrm{~d}^{\prime}$ transitions) and Ar IV (4s - 4p and $4 \mathrm{~s}^{\prime}-4 \mathrm{p}^{\prime}$ transitions) spectra, some of the existing transition probability values $(A)$ have been controlled. On the basis of the confirmed $A$ values in Ar III $(328.585 \mathrm{~nm}, 330.188 \mathrm{~nm}, 331.125 \mathrm{~nm}, 333.613 \mathrm{~nm}$ and $334.472 \mathrm{~nm})$ and in Ar IV (280.944 nm and $278.896 \mathrm{~nm}$ ) spectra two $A$ values in Ar III and seven $A$ values in Ar IV spectra have been determined, for the first time, relatively to the confirmed $A$ values. Beside, some of the existing theoretical $A$ data have been corrected, according to our experimentally observed relative line intensity ratio values. Measurements have been performed
\end{abstract} \\ by using the linear low pressure pulsed arc, as an optically thin plasma source, operated in argon-helium mixture.
}

Key words. lines: atomic-data - transition probabilities - relative line intensity ratios

\section{Introduction}

Transition probability of spontaneous emission (Einstein's $A$ value) plays an important role in plasma and laser investigation and, also, in astrophysics. Namely, various kinetic processes appearing in plasma modeling need reliable knowledge of $A$ values (Griem 1964, 1974, 1997). Beside, knowledge of the $A$ values gives possibility for determination the coefficients of the absorption and stimulated emission. These processes are also important in the astrophysics and laser physics. However, the existing $A$ values (Wiese et al. 1966, 1969; Lide 1994), for number of emitters, are given with high uncertainties. These values are calculated on the basis of the Coulomb approximation (Allen 1973) or by using the Self-Consistent Field (SCF) method (Hartree 1956). In the case of ionized emitters (doubly or triply ionized argon, as example) the expected uncertainties are $50 \%$ or larger (Wiese et al. 1969). On the other hand, known experimental techniques show various difficulties (Wiese et al. 1966; Wiese 1968; Rompe \& Steenbeck 1967) which limit accuracy of the measured $A$ values.

In this work the transition probabilities of spontaneous emission of eight transitions in Ar III and seventeen transitions in Ar IV spectrum have been obtained using the relative line intensity ratios method. The selected spectral lines are the strongest in the Ar III and Ar IV spectra and they are frequently applied in different sort of investigations. The total line intensities $(I)$ have been measured

Send offprint requests to: S. Djeniže with high accuracy $(3 \%-5 \%)$ using the step-by-step technique for the line profiles recording. Measurements were performed using the linear pulsed arc plasma as the optically thin radiation source (Djeniže et al. 1991, 1998, 2000b), in Local Thermodynamic Equilibrium (LTE). In this case the well-known formula (Griem 1964):

$\left(I_{1} / I_{2}\right)_{\exp }=\left(A_{1} g_{1} \lambda_{2} / A_{2} g_{2} \lambda_{1}\right) \exp \left(\Delta E_{21} / k T\right)$

can be used for a comparison between measured relative line intensity ratios and corresponding calculated values taking into account validity of the Boltzmann distribution for population of the excited levels in emitters. $I, \lambda, A, E$ and $g$ in the Eq. (1) denote measured relative intensity, wavelength of the transition, transition probability of the spontaneous emission in researched particular quantum transition, excitation energy from the ground energy level and corresponded statistical weight, respectively. $T$ is the electron temperature of the plasma in LTE and $k$ is the Boltzmann constant. In the case when compared spectral lines belong to the same multiplet, Eq. (1) can be rewritten in the form:

$\left(I_{1} / I_{2}\right)_{\exp }=A_{1} g_{1} / A_{2} g_{2}$

because of the very small difference between excitation energies and wavelengths related to the compared lines. Equation (2) gives possibility to check the existing $A$ values associated to the transitions within a multiplet. 
We have monitored ratios $\left(I_{1} / I_{2}\right)_{\exp }$ for a spectral lines that belong to the same multiplet in a wide range of the decaying plasma up to the moment when the line intensity maximum dropped down to $10 \%$ of its maximal value. We have found that these experimental ratios are constant within $6 \%$ during the plasma decay. This suggest that the comparison between measured and calculated relative line intensity ratios can be employed as a method for estimation of the transition probabilities relatively to the selected referent $A$ values. Namely, we suppose that there is at least one pair of lines, belonging to the same multiplet, for which measured and calculated relative line intensity ratios are in agreement (within the accuracy of the measurements) during the whole plasma decay period. If such agreement really exist one can accept these lines, with corresponding transition probabilities, as the referent. Among the lines that we have investigated such behavior is found for the: $328.585 \mathrm{~nm}, 330.188 \mathrm{~nm}, 331.125 \mathrm{~nm}, 333.613 \mathrm{~nm}$ and $334.472 \mathrm{~nm}$ Ar III and $280.944 \mathrm{~nm}$ and $278.896 \mathrm{~nm}$ Ar IV transitions. Existing theoretical $A$ values of these lines (Wiese et al. 1969) can be accepted as experimentally confirmed, reliable, atomic data. Furthermore, these $A$ values can be used as reference for relative determination of unknown transition probability values for transitions that belong to the different multiplets. Using the Eqs. (1) and (2) we have found that one of the existing $A$ values in the investigated Ar III transition needs correction. In the investigated Ar IV transition we have corrected eight $A$ values. Beside, two $A$ values, not known before (Wiese et al. 1969, NIST-Database), were obtained in the case of the Ar III and seven $A$ values in the case of Ar IV spectrum, relatively to the mentioned Ar III and Ar IV referent $A$ values.

\section{Experiment}

The modified version of the linear low pressure pulsed arc (Djeniže et al. 1991, 1998, 2000b) has been used as a plasma source. A pulsed discharge was driven in a quartz discharge tube of $5 \mathrm{~mm}$ inner diameter and effective plasma length of $7.2 \mathrm{~cm}$ (Fig. 1 in Djeniže et al. 1991, 1998). The tube has end-on quartz windows. On the opposite side of the electrodes the glass tube was expanded in order to reduce erosion of the glass wall and also sputtering of the electrode material onto the quartz windows. The working gas was argon-helium mixture $(72 \%$ $\mathrm{Ar}+28 \% \mathrm{He})$ at $130 \mathrm{~Pa}$ filling pressure with constant flux $(6 \mathrm{ml} / \mathrm{min})$ flowing regime. Chosen flux and pressure provide minimal self-absorption of the investigated spectral lines. Spectroscopic observation of isolated spectral lines were made end-on along the axis of the discharge tube. A capacitor of $14 \mu \mathrm{F}$ was charged up to $2.5 \mathrm{kV}$. The line profiles were recorded using a step-by-step technique with a photomultiplier (EMI 9789 QB) and a grating spectrograph (Zeiss PGS-2, reciprocal linear dispersion $0.73 \mathrm{~nm} / \mathrm{mm}$ in first order) system. The system was calibrated by using the EOA-101 standard lamp located at $40 \mathrm{~cm}$ distance from the spectrograph input slit. The

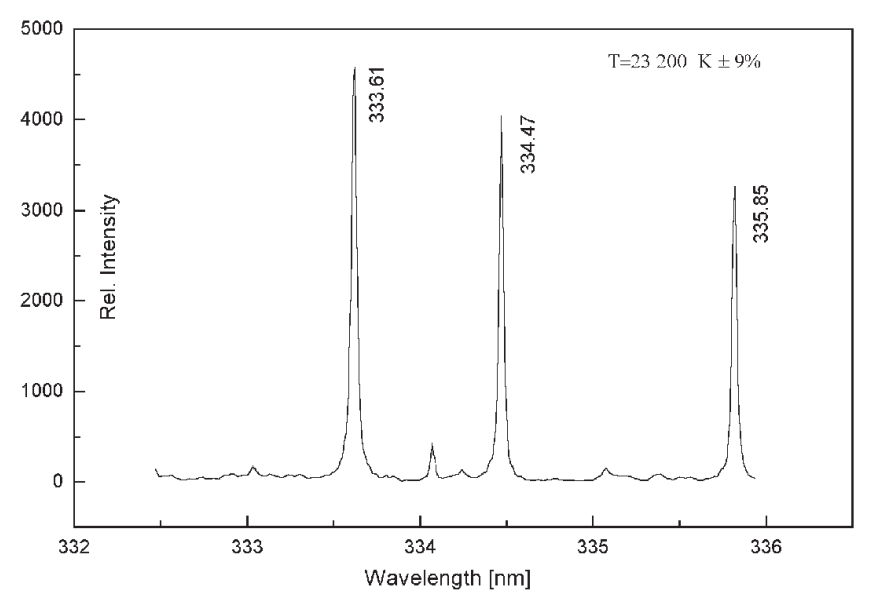

Fig. 1. Recorded Ar III spectrum at the 20th $\mu$ s after the beginning of the discharge

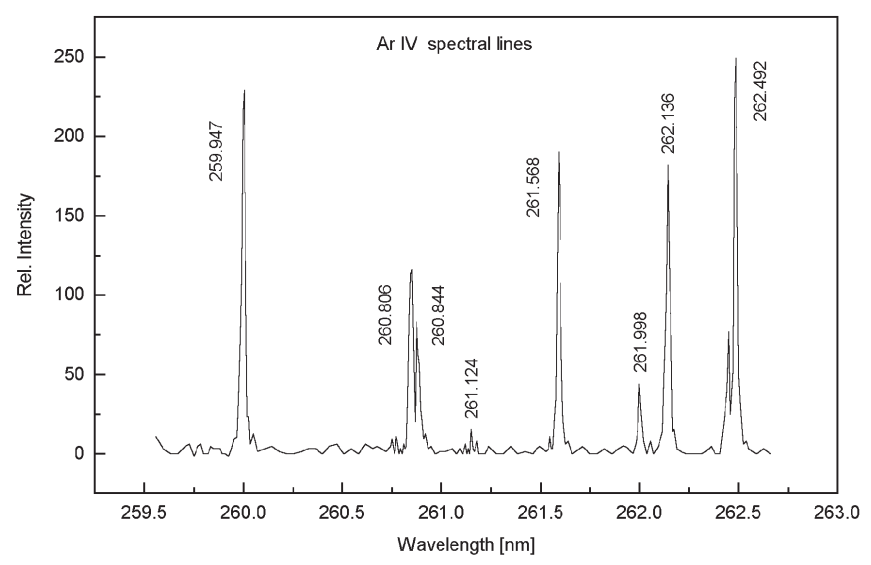

Fig. 2. Recorded Ar IV spectrum at the 15 th $\mu$ s after the beginning of the discharge

instrumental FWHM of $0.008 \mathrm{~nm}$ was determined by using the narrow spectral lines emitted by the hollow cathode discharge. The spectrograph exit slit $(10 \mu \mathrm{m})$ with the calibrated photomultiplier was micrometrically traversed along the spectral plane in small wavelength steps $(0.0073 \mathrm{~nm})$. The averaged photomultiplier signal (five shots at each position) was digitized using an oscilloscope, interfaced to a computer. All spectral line profiles have been recorded at the same detection conditions. A sample spectra, as example, are shown in Figs. 1 and 2.

Plasma reproducibility was monitored by the Ar II, Ar III and Ar IV lines radiation and, also, by the discharge current using Rogowski coil signal (it was found to be within $\pm 3 \%$ ). Recorded line profiles can be fitted to the Voigt function as a convolution of the Gauss (instrumental and Doppler broadening) and Lorentz (Stark broadening) functions. The standard deconvolution procedure (Davies \& Vaughan 1963) was computerized using the least square algorithm. Total line intensity (I) corresponds to the area under the line profile. One can notice, see Figs. 1 and 2, that investigated spectral lines are well isolated while the continuum is close to the zero value within the same 


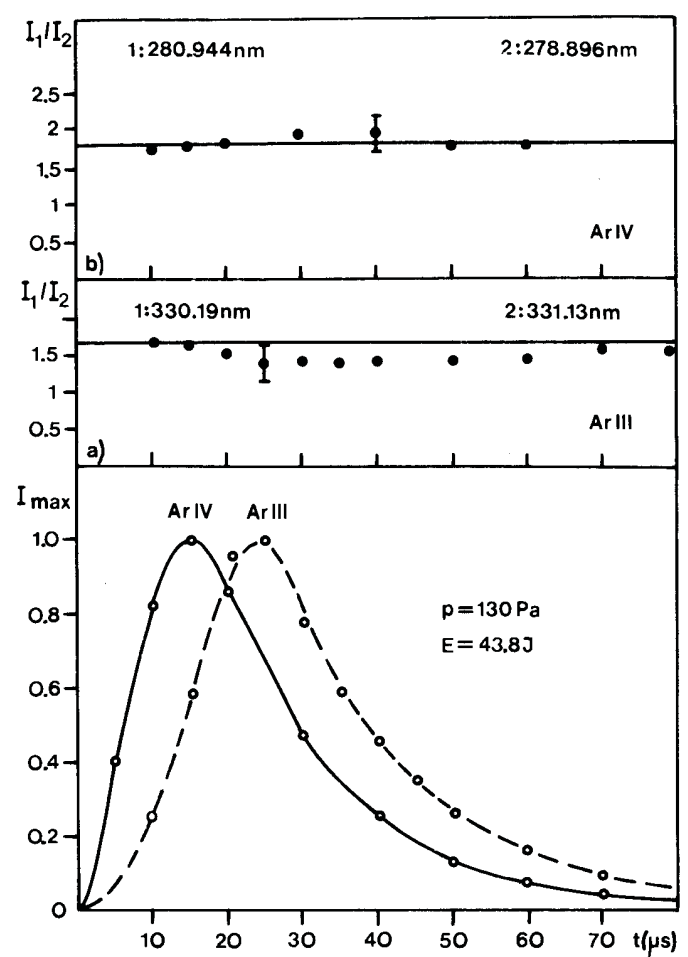

Fig. 3. Temporal evolution of normalized line intensity maximum $\left(I_{\max }\right)$ averaged over 17 researched lines of Ar IV and 8 researched lines of Ar III. Temporal dependence of the relative line intensity ratios are also presented for the lines that belong to the low lying Ar III a) and Ar IV b) multiplets (see also Table 1)

range of wavelengths. These facts are important for accurate determination of the total line intensities and these conveniences increase reliability of the results.

The intensity maximum $\left(I_{\max }\right)$ of the Ar III and Ar IV spectral lines were monitored during the plasma decay. Temporal evolutions of the normalized $I_{\max }$ values are presented in Fig. 3.

It is evident that Ar IV lines reach maximal intensity $15 \mu$ s after beginning of the discharge which correspond to the moment of maximal electron density. Temporal dependence of the line intensity of Ar III lines has a similar flow, but maximal intensity is reached $25 \mu$ s after beginning of the discharge. In these moments $(15 \mu \mathrm{s}$ and $25 \mu \mathrm{s}$, respectively) the maximal density of the Ar IV and Ar III species are expected. This is important for estimation of self-absorption. Namely, maximal self-absorption is expected to be in the mentioned moments. In order to minimize influence of the self-absorption on the total line intensity great care was taken to find optimal discharge conditions (gas pressure, flux, bank-energy, selfinductance). Found optimal values have been noticed above in the text. To check existence of the self-absorption, relative line intensity ratios have been controlled during the plasma decay. Absence of the self-absorption would cause constant relative line intensity ratio. This is fulfilled in the case of the low lying $\left({ }^{4} \mathrm{P}-{ }^{4} \mathrm{D}^{0}\right)$ multiplet in $\mathrm{Ar} I \mathrm{~V}$

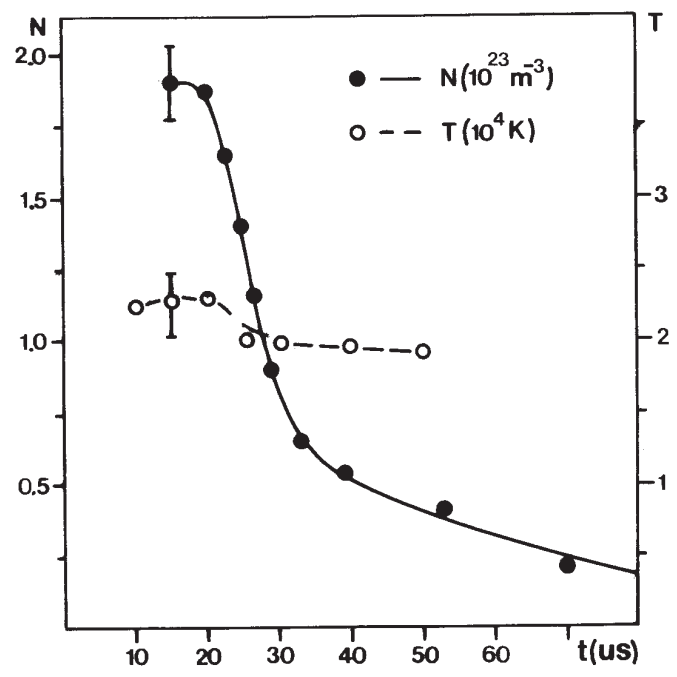

Fig. 4. Temporal evolution of the electron temperature $(T)$ and electron density $(N)$ during the plasma decay

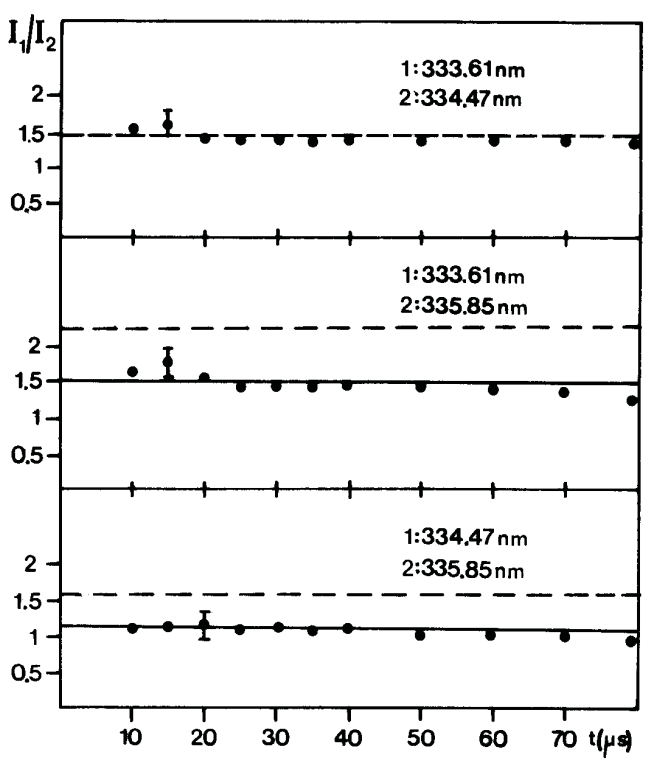

Fig. 5. Relative line intensity ratios $\left(I_{1} / I_{2}\right)$ during the plasma decay. •, our experimental values within $\pm 10 \%$ accuracy. - - -, theoretical ratios by using the existing transition probability values from Wiese (1969) and Lide (1994) within estimated uncertainties of $50 \%$. Solid lines represent theoretical intensity ratios after the correction of the transition probabilities. All three lines belong to the same multiplet (No. 3) in the Ar III spectrum

spectrum (Fig. 3b). Therefore, influence of the self absorption on the total line intensity values for Ar IV lines can be neglected. In the case of low lying $\left({ }^{5} S^{0}-{ }^{5} \mathrm{P}\right)$ multiplet in Ar III spectrum relative line intensity ratio cease to be constant at the 20 th $\mu$ s after beginning of the discharge testifying presence of the self absorption (Fig. 3a). Similarly, one can notice absence of the self absorption for upper lying Ar III and Ar IV multiplets, see Figs. 5-7. From this fact follows that for employed experimental 
Table 1. Obtained transition probability values $\left(A_{\exp }\right)$ with their estimated accuracy's. $A_{\mathrm{w}}$ are existing probability values taken from Wiese et al. (1969) and from NIST-Database. $A_{\mathrm{K}}$ denote calculated values by Kurucz $(2000)$. $E_{\mathrm{u}}$ and $g_{\mathrm{u}}$ denote the upper-level excitation energy and corresponding statistical weight, respectively. $J_{\mathrm{u}}$ and $J_{1}$ are the inner quantum numbers corresponding to the upper $(\mathrm{u})$ and lower $(\mathrm{l})$ energy levels in the particular quantum transition with given wavelength $(\lambda)$ in the researched multiplet

\begin{tabular}{|c|c|c|c|c|c|c|c|c|c|}
\hline Emitter & Transition & Multiplet & $J_{1}-J_{\mathrm{u}}$ & $\begin{array}{c}\lambda \\
(\mathrm{nm})\end{array}$ & $\begin{array}{c}E_{\mathrm{u}} \\
(\mathrm{eV})\end{array}$ & $g_{\mathrm{u}}$ & $\begin{array}{c}A_{\mathrm{w}} \\
\left(10^{8} \mathrm{~s}^{-1}\right)\end{array}$ & $\begin{array}{c}A_{\exp } \\
\left(10^{8} \mathrm{~s}^{-1}\right)\end{array}$ & $\begin{array}{c}A_{\mathrm{K}} \\
\left(10^{8} \mathrm{~s}^{-1}\right)\end{array}$ \\
\hline \multirow{8}{*}{ Ar III } & $4 s-4 p$ & ${ }^{5} \mathrm{~S}^{0}-{ }^{5} \mathrm{P}$ & $2-3$ & 328.585 & 25.39 & 7 & $2.0 \pm 50 \%$ & $2.00 \pm 10 \%$ & 2.096 \\
\hline & & (1) & $2-2$ & 330.188 & 25.37 & 5 & $2.0 \pm 50 \%$ & $2.00 \pm 10 \%$ & 2.057 \\
\hline & & & $2-1$ & 331.125 & 25.36 & 3 & $2.0 \pm 50 \%$ & $2.00 \pm 10 \%$ & 2.054 \\
\hline & $4 \mathrm{~s}^{\prime}-4 \mathrm{p}^{\prime}$ & ${ }^{3} \mathrm{D}^{0} \_{ }^{3} \mathrm{~F}$ & $3-4$ & 333.613 & 28.10 & 9 & $2.0 \pm 50 \%$ & $2.00 \pm 10 \%$ & 1.960 \\
\hline & & (3) & $2-3$ & 334.472 & 28.08 & 7 & $1.8 \pm 50 \%$ & $1.80 \pm 10 \%$ & 1.734 \\
\hline & & & $1-2$ & 335.849 & 28.06 & 5 & $1.6 \pm 50 \%$ & $2.35 \pm 15 \%$ & 1.628 \\
\hline & $4 \mathrm{p}^{\prime}-4 \mathrm{~d}^{\prime}$ & ${ }^{3} \mathrm{P}^{0}-{ }^{3} \mathrm{P}^{0}$ & $2-2$ & 248.886 & 33.66 & 5 & - & $1.30 \pm 20 \%$ & 4.101 \\
\hline & & ${ }^{3} \mathrm{P}-{ }^{3} \mathrm{P}^{0}$ & $0-1$ & 250.442 & 33.68 & 3 & - & $0.45 \pm 20 \%$ & 1.735 \\
\hline \multirow[t]{17}{*}{ Ar IV } & $4 s-4 p$ & ${ }^{4} \mathrm{P}-{ }^{4} \mathrm{D}^{0}$ & $5 / 2-7 / 2$ & 280.944 & 35.65 & 8 & $2.6 \pm 50 \%$ & $2.60 \pm 10 \%$ & 2.591 \\
\hline & & $(4 \mathrm{UV})$ & $3 / 2-5 / 2$ & 278.896 & 35.55 & 6 & $1.9 \pm 50 \%$ & $1.90 \pm 10 \%$ & 1.840 \\
\hline & & & $1 / 2-3 / 2$ & 277.626 & 35.49 & 4 & $1.1 \pm 50 \%$ & $1.60 \pm 10 \%$ & 1.109 \\
\hline & & & $3 / 2-3 / 2$ & 283.025 & 35.49 & 4 & $1.4 \pm 50 \%$ & $1.65 \pm 10 \%$ & 1.343 \\
\hline & & ${ }^{4} \mathrm{P}-{ }^{4} \mathrm{P}^{0}$ & $5 / 2-5 / 2$ & 264.034 & 35.93 & 6 & $2.2 \pm 50 \%$ & $1.65 \pm 15 \%$ & 2.200 \\
\hline & & $(5 \mathrm{UV})$ & $3 / 2-3 / 2$ & 260.806 & 35.86 & 4 & $0.43 \pm>50 \%$ & $1.00 \pm 15 \%$ & 0.436 \\
\hline & & & $3 / 2-1 / 2$ & 261.568 & 35.85 & 2 & $2.7 \pm 50 \%$ & $2.60 \pm 10 \%$ & 2.677 \\
\hline & & ${ }^{4} \mathrm{P}-{ }^{4} \mathrm{~S}^{0}$ & $5 / 2-3 / 2$ & 251.328 & 36.17 & 4 & - & $2.25 \pm 15 \%$ & 1.911 \\
\hline & & $\begin{array}{c}{ }^{2} \mathrm{P}-{ }^{2} \mathrm{D}^{0} \\
(2)\end{array}$ & $1 / 2-3 / 2$ & 292.633 & 35.99 & 4 & $2.0 \pm 50 \%$ & $4.50 \pm 15 \%$ & 1.992 \\
\hline & & ${ }^{2} \mathrm{P}-{ }^{2} \mathrm{P}$ & $3 / 2-1 / 2$ & 260.844 & 36.66 & 2 & - & $1.90 \pm 17 \%$ & 1.175 \\
\hline & & ${ }^{2} \mathrm{P} \_{ }^{2} \mathrm{P}^{0}$ & $3 / 2-3 / 2$ & 259.947 & 36.67 & 4 & - & $2.50 \pm 15 \%$ & 2.965 \\
\hline & & & $1 / 2-1 / 2$ & 252.569 & 36.66 & 2 & - & $2.00 \pm 15 \%$ & 2.619 \\
\hline & $4 \mathrm{~s}^{\prime}-4 \mathrm{p}^{\prime}$ & ${ }^{2} \mathrm{D}-{ }^{2} \mathrm{~F}^{0}$ & $5 / 2-7 / 2$ & 275.792 & 37.74 & 8 & $2.8 \pm 50 \%$ & $3.85 \pm 17 \%$ & 2.752 \\
\hline & & $(6 \mathrm{UV})$ & $3 / 2-5 / 2$ & 278.447 & 37.70 & 6 & $2.5 \pm 50 \%$ & $4.30 \pm 17 \%$ & 2.490 \\
\hline & & ${ }^{2} \mathrm{D}^{0}-^{2} \mathrm{D}^{0}$ & $5 / 2-5 / 2$ & 262.492 & 37.97 & 6 & - & $3.35 \pm 17 \%$ & 3.144 \\
\hline & & & $3 / 2-3 / 2$ & 262.136 & 37.98 & 4 & - & $3.60 \pm 17 \%$ & 3.053 \\
\hline & & & $5 / 2-3 / 2$ & 261.998 & 37.98 & 4 & - & $0.80 \pm 17 \%$ & 0.343 \\
\hline
\end{tabular}

conditions (spatial distribution, discharge characteristics, gas pressure etc.) our plasma can be considered as optically thin. On the other hand, Stark width values of these lines measured by Djeniže et al. (2000a,b) in the same plasma conditions agree well with existing experimental and theoretical Stark width values testifying, also, the absence of the self-absorption. Therefore, presented results show that the relative line intensity ratio method is suitable for checking of the self-absorption (Wiese 1968; Griem 1964, 1974).

The plasma parameters were determined using standard diagnostic methods (Rompe \& Steenbeck 1967). Thus, the electron temperature was determined from the Boltzmann-plot of seven Ar III lines (330.2; 331.1; 335.8; $334.5 ; 333.6 ; 248.9$ and $250.4 \mathrm{~nm}$ ) with a corresponding upper-level energy interval of $8.32 \mathrm{eV}$ with an estimated error of $\pm 9 \%$, assuming the existence of LTE, according to criterion from Griem (1974). Necessary atomic data were taken from Wiese et al. (1969); Striganov \& Sventickii (1996) and from Table 1 in this work. Form of the electron temperature decay is presented in Fig. 4. The electron density decay was measured using a well-known single laser interferometry (Ashby et al. 1965) technique for the $632.8 \mathrm{~nm}$ He-Ne laser wavelength with an estimated error of $\pm 7 \%$ and, also, by Stark width measurements of the convenient He II $\mathrm{P}_{\alpha}(468.57 \mathrm{~nm})$ line (Pittman \& Fleurier 1986). The electron density decay is presented, also, in Fig. 4 .

Taking into account temporal dependencies of $T$ and $N$ and the criterion for the existence of the LTE (Griem 1974), we can conclude that our plasma abide in the state of the LTE up to the 70th $\mu$ s after the beginning of the discharge. Therefore, the Eq. (1) can be applied up to this moment. 


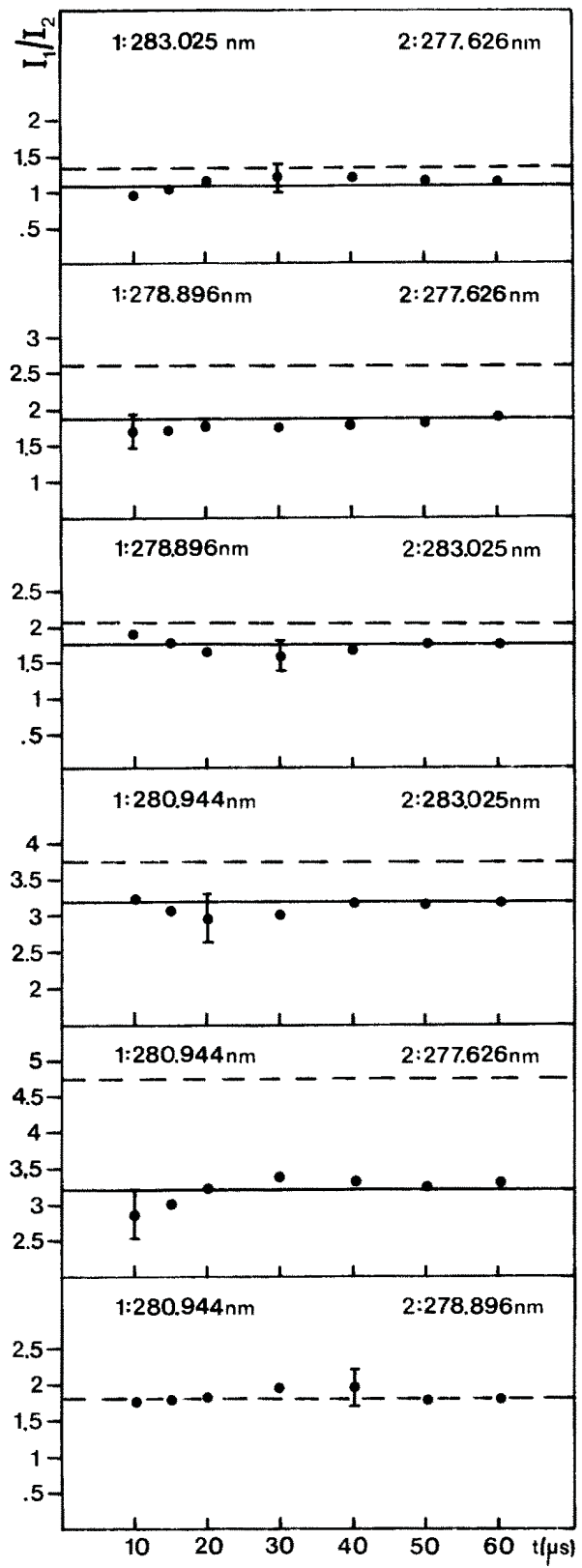

Fig. 6. Same as in the Fig. 5, but for the Ar IV 4UV multiplet

\section{Results}

Relative line intensity ratios measured for the lines within the same multiplet are presented in Figs. 5-7.

It is evident that relative line intensity ratios show tolerable scattering of the same magnitude during the whole plasma decay period. This fact, confirm the absence of the self-absorption. Ratio $\left(I_{1} / I_{2}\right)$ for the Ar III $333.613 \mathrm{~nm}$ and $334.472 \mathrm{~nm}$ lines (multiplet No. 3) show very good agreement with the theoretical line intensity ratio (Fig. 5) calculated using the existing transition probability values from Wiese et al. (1969). Similar behavior is present in the case of the $280.944 \mathrm{~nm}$ and $278.896 \mathrm{~nm}$ Ar IV spectral lines (Fig. 6). These facts allow us to believe that the existing

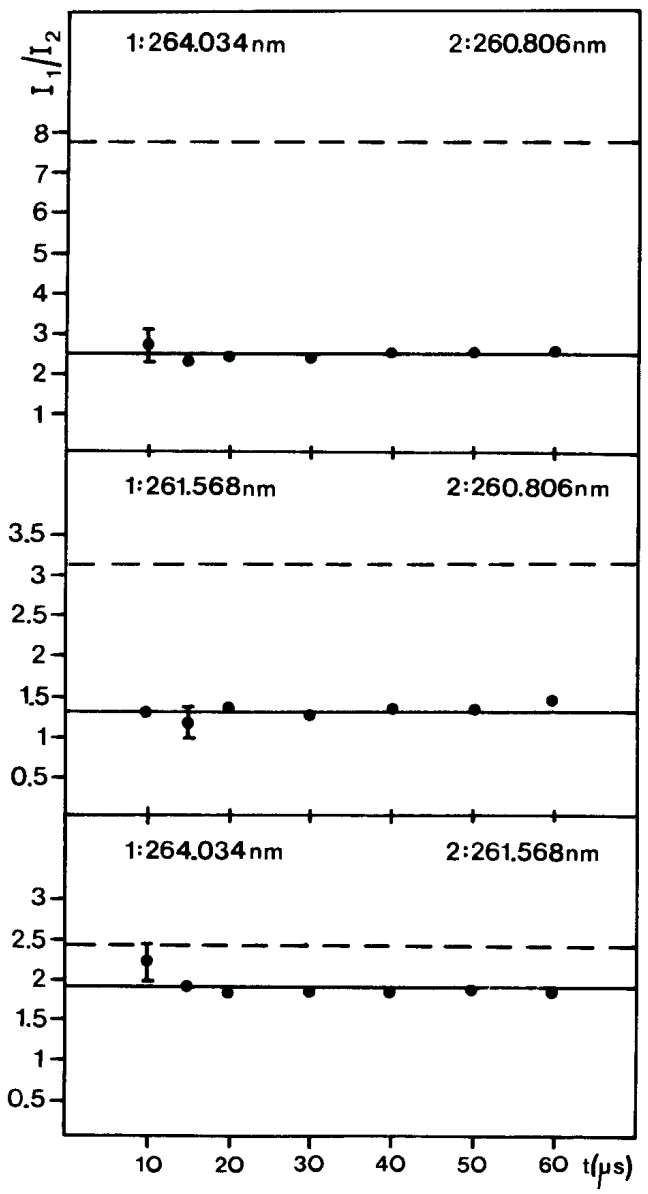

Fig. 7. Same as in the Fig. 5, but for the Ar IV 5UV multiplet

$A$ values, of the same spectral lines, calculated on the basis of the $L S$ coupling (Wiese et al. 1969 and references therein) are correct. Using the Eqs. (1) and (2) the $A$ values of the other quantum transitions are obtained, relative to the confirmed A values mentioned above. Found $A_{\exp }$ values are presented in the Table 1 together with the existing calculated $A$ values taken from various data sources (Wiese et al. 1969; NIST - Atomic Spectra Database 2000; Kurucz Database 2000).

\section{Conclusion}

We have obtained $A$ values for two Ar III (248.886 nm and $250.442 \mathrm{~nm}$ ) and seven Ar IV transitions (251.328 nm, $260.844 \mathrm{~nm}, 259.947 \mathrm{~nm}, 252.569 \mathrm{~nm}, 262.492 \mathrm{~nm}$, $262.136 \mathrm{~nm}$ and $261.998 \mathrm{~nm})$ not evident by NIST database. Beside, one Ar III (335.849 nm) and eight Ar IV (277.626 nm, 283.025 nm, 264.034 nm, 260.806 nm, $261.568 \mathrm{~nm}, 292.633 \mathrm{~nm}, 275.792 \mathrm{~nm}$ and $278.447 \mathrm{~nm})$ existing $A$ values have been corrected. These corrections are most significant for the $260.806 \mathrm{~nm}$ and $292.633 \mathrm{~nm}$ Ar IV transitions (about $+130 \%$ and $+125 \%$, respectively). All new values are relative to the confirmed $A$ values that belong to the transitions in low lying multiplets in the Ar III and Ar IV spectra. Our experimentally obtained 
$A$ values are in satisfactory agreement with those from Kurucz (2000) in the case of the $251.328 \mathrm{~nm}, 260.844 \mathrm{~nm}$, $259.947 \mathrm{~nm}, 252.569 \mathrm{~nm}, 262.492$ and $262.136 \mathrm{~nm}$ Ar IV spectral transitions. It should be pointed out that small number of papers deal with the Ar III and Ar IV transition probability values (Wiese et al. 1969; Lide 1994; NIST-Database; Kurucz - Database). New theoretical calculations of these values would be helpful.

\section{References}

Allen, C. W. 1973, Astrophysical Quantities, 3rd ed. (The Athlone Press, London)

Ashby, D. E. T. F, Jephcott, D. F., Malein, A., \& Raynor, A. 1965, Appl. Phys., 36, 29

Davies, J. T., \& Vaughan, J. M. 1963, ApJ, 137, 1302

Djeniže, S., Srećković, A., Labat, J., Konjević, R., \& Popović, L. Č. 1991, Phys. Rev. A., 44, 410

Djeniže, S., Milosavljević, V., \& Srećković, A. 1998, JQSRT, 59,71

Djeniže, S., Bukvić, S., \& Mišković, D. 2000a, Publ. Astron. Obs. Belgrade, 67, 53

Djeniže, S., Bukvić, S., \& Mišković, D. 2000b, A\&AS, submitted

Griem, H. R. 1964, Plasma Spectroscopy (Mc Graw-Hill, New York)
Griem, H. R. 1974, Spectral Line Broadening by Plasmas (Acad. Press, New York)

Griem, H. R. 1997, Principles of Plasma Spectroscopy (Cambridge Univ. Press. Cambridge)

Hartree, D. R. 1956, The Calculation of Atomic Structures (John Willey \& Sons, New York)

Kurucz, R. L. 2000, Harvard-Smitshonian Center for Astrophysics, CDRoom-23

Lide, D. R. (Editor-in-Chief) 1994, CRC Handbook of Chemistry and Physics, 74th edition (CRC Press, Boca Raton, USA)

NIST-Atomic Spectra Database Lines Data, Wavelengths ordered

Pittman, T. L., \& Fleurier, C. 1986, Phys. Rev. A, 33, 1291

Rompe, R., \& Steenbeck, M. 1967, Ergebnisse der Plasmaphysik und der Gaselektronik, Band 1 (Akademie Verlag, Berlin)

Striganov, R. A., \& Sventickii, N. S. 1966, Tablici Spectralnjih Linii, Atomizdat, Moscow

Wiese, W. L., Smith, M. W., \& Glennon, B. M. 1966, Atomic Transition Probabilities, vol. I NSRDS-NBS 4 (DC.V.S. Government Printig Office, Washington)

Wiese, W. L., Smith, M. W., \& Miles, B. M. 1969, Atomic Transition Probabilities, vol. II NSRDS-NBS 22 (DC.V.S. Government Printing Office, Washington)

Wiese, W. L. 1968, in Methods of Experimental Physics, ed. B. Bederson, \& W. L. Fite, vol. 7B (Academic, New York) 